\title{
O EFEITO MODIFICATIVO DOS EMBARGOS DE DECLARAÇÃO E O CPC DE 2015
}

THE MODIFICATION EFFECT OF DECLARATION BOARDS AND THE 2015 CPC

Guilherme Francisco SEARA ARANEGA ${ }^{1}$

Michel Vieira de VASCONCELOS ${ }^{2}$

ISSUE DOI: $10.21207 / 1983.4225 .846$

\begin{abstract}
RESUMO
Os embargos de declaração existem desde os tempos dos monarcas e, ainda assim, seu desenvolvimento e estudo perfizeram pontos controvertidos durante o caminhar da história. O efeito modificativo dos embargos de declaração traz em seu bojo anos de discussão sobre as questões que o envolvem. A análise desse efeito dos embargos de declaração sob a ótica do Código de Processo Civil, advindo da Lei $\mathrm{n}^{\circ} 13.105 / 2015$, demonstra que, quando da oposição do recurso, objetivando suprir omissão, clarear obscuridade, corrigir erro material ou eliminar contradição, é possível o resultado de modificação da decisão, alterando o intuito decisório. Demonstra-se com o presente trabalho, portanto, quais são as possibilidades de utilização de tal regra processual e a posição adotada atualmente nos principais Tribunais.
\end{abstract}

1 Professor na Especialização da Faculdade Maringá-CESPAR (Maringá-PR); - Professor na Graduação e Especialização da Faculdade SMG (Maringá-PR); - Mestre em Ciências Jurídicas pela UniCesumar; - Especialista em Direito Processual Civil, Direito Civil e Docência no Ensino Superior pelo Instituto Paranaense de Ensino - IPE; - Sócio-proprietário no escritório de advocacia empresarial Aranega, Prade, Gerber Advogados; - Presidente da Comissão da Advocacia Contenciosa da ABA Associação Brasileira dos Advogados de Maringá-PR; - Membro Consultivo da Comissão de Direito Digital e Inovação da OAB de Maringá-PR; - Conselheiro da OAB Maringá-PR (gestão 2019/2021). http://lattes.cnpq.br/6489212865604339.

${ }^{2}$ Graduado em Direito pela Faculdade Santa Maria da Glória de Maringá-PR. Pós-graduando em Direito Imobiliário pela Unicesumar. Advogado. Contato: mvvasconcelos@outlook.com. http://lattes.cnpq.br/2576525411499974. 
Palavras-chave: Novo CPC; Efeito Modificativo; Código de Processo Civil; Recursos; Impugnação de Decisões Judiciais.

\begin{abstract}
Declaration embargoes have existed since the time of the monarchs, and yet their development and study have become controversial points during the course of history. The modifying effect of the embargoes of declarations brings in its bulge years of discussion on the issues that involve it. The analysis of this effect of the declaration embargoes from the point of view of the Code of Civil Procedure, derived from Law 13.105/2015, shows that, when opposition is filed, to remedy omission, clarify obscurity, correct material error or eliminate contradiction, it is possible the result of modifying the decision, changing the decision-making intent. It is demonstrated with the present work, therefore, what are the possibilities of using such procedural rule and the position currently adopted in the main Courts.
\end{abstract}

Keywords: New civil procedure code; Modifying Effect; Code of Civil Procedure; Resources; Challenging Judgments.

\title{
INTRODUÇÃO
}

Os recursos no processo civil são meios de insurgir sobre decisões que a parte processual não esteja satisfeita com o resultado. São manejados com o intuito de viabilizar reexame da matéria na relação jurídica ou pontos específicos e estruturais, requerendo a reforma, anulação, aclaramento ou integração da decisão ora impugnada.

Acerca das possibilidades recursais que figuram no Código de Processo Civil de 2015, dentre elas a apelação, o recurso ordinário constitucional, o agravo interno, o agravo de instrumento, o recurso extraordinário e o recurso especial, escolhe-se a figura dos embargos de declaração para análise de suas nuances e especialmente para demonstrar que, com o advento da nova lei processual civil com entrada em vigor em 18 de março de 2016, os embargos de declaração passaram a ter aspecto positivado de um possível novo efeito ou consequência, o modificativo ou infringente. Essa nova modalidade amplia a aplicação dos embargos declaratórios, expandindo seu horizonte.

No presente artigo científico serão tratados em caráter genérico os recursos civis, com breve escorço sobre as principais características, qual momento correto para sua aplicação e quais suas finalidades. Em seguida, passar-se-á arrazoar a respeito dos embargos de declaração, descrevendo suas nuances, seus efeitos, possibilidades e adequações. E, por fim, ao ponto fulcral do artigo, o efeito modificativo dos embargos de declaração à luz do Código de Processo Civil de 2015. 


\section{$2 \quad$ RECURSOS PROCESSUAIS CIVIS E O CPC 2015}

A conceituação do instituto dos recursos cíveis é o ponto de partida para iniciar a temática processual a ser tratada no presente artigo. No sentido amplo e jurídico da palavra, recurso significa pedir ajuda, auxílio, ou até mesmo dar solução. Compreender que o recurso é uma forma de solicitar ajuda, por mais simples que pareça, facilitará demasiadamente no decorrer do assunto. Antes de levar essa conceituação para o âmbito jurídico estrito pautado em cada modalidade recursal, devese por cautela, entender qual momento oportuno o recurso incidirá.

Pois bem, os conflitos de ordem econômica, moral, patrimonial, social, entre tantas outras possibilidades, quando dotadas de elementos que soneguem algum direito alheio, possivelmente se transformarão em um processo judicial. Esse processo percorrerá um procedimento, subdivido em especial ou comum. O procedimento representa a marcha do processo, qual caminho ele percorrerá, disciplinando seu desenvolvimento conforme as partes vão se manifestando.

No início (petição inicial), a parte que estiver demandando promoverá argumentos sobre os fatos ocorridos, fundamentará juridicamente seu direito, e ao final, após exposto o que pretende com a demanda, exporá seus pedidos. A partir do protocolo dessa peça processual, iniciar-se-á efetivamente o chamado processo de conhecimento, onde o processo cursará um caminho que se deparará com controvérsias, tanto da parte contrária, quanto possivelmente do magistrado.

É nesse momento - quando surgem as controvérsias - que o recurso pode entrar em cena.

Portanto, por esse aspecto, o recurso passa a ser necessário para que as decisões possam ser modificadas, de modo que passam a fazer parte intrinsicamente do caminhar do processo. Desse modo, os recursos são munidos de características tanto de impugnar a decisão recorrida, quanto de provocar o reexame da matéria.

Os recursos no Código de Processo Civil de 2015 estão estabelecidos no título II do Livro III na parte Especial.

Mudanças significativas aconteceram de um código (Código de Processo Civil de 1973) para o outro (Código de Processo Civil de 2015). Sobre a contagem de prazos recursais, houve uma unificação do tempo disponível para interpor cada recurso, passando a ser quinze dias para todos 
os recursos, com exceção dos embargos de declaração que continua com cinco dias de prazo. E ainda, ficou estabelecido que os prazos sejam contados em dias úteis (art. 219 do Código de Processo Civil), o que é regra geral de contagem de prazos que influencia diretamente na funcionalidade e utilização dos recursos.

Outra questão importante, a uniformização dos precedentes prevista expressamente no art. 926, foi uma das ferramentas utilizadas nesse novo diploma processual na tentativa de dar maior celeridade ao processo. Esse novo sistema de precedentes, com o passar do tempo e consequentemente com o maior número de julgamentos, impedirá que as decisões nos Tribunais contenham divergências sobre demandas similares.

Neste novo diploma processual civil o legislador enumerou os recursos possíveis para as ações cíveis, previstos no artigo 994, sendo eles: apelação, agravo de instrumento, agravo interno, embargos de declaração, recurso ordinário, recurso especial, recurso extraordinário, agravo em recurso especial ou extraordinário e embargos de divergência. Ainda, no artigo 996 do mesmo diploma legal, delimitou-se quem pode interpor o recurso: parte vencida, terceiro prejudicado e pelo Ministério Público.

\section{EMBARGOS DE DECLARAÇÃO}

Originariamente, advindo do direito português, os embargos de declaração foram trazidos ao ordenamento processual brasileiro com o objetivo de corrigir decisões proferidas em meios às ações judiciais intentadas no país.

No Brasil, há registros da utilização dos embargos pelas Ordenações Afonsinas (Livro III das Ordenações Afonsinas), Filipinas (Livro III, título 66, $\S 6^{\circ}$ ) e também nas Ordenações Manuelinas (Livro III, título $\left.50, \S 5^{\circ}\right)$.

Sequencialmente, no ano de 1850 , precisamente no Decreto $\mathrm{n}^{\circ}$ 737 de 25 de novembro, os embargos de declaração pertenceram ao rol dos recursos, apontando a sua interposição via petição dirigida ao juiz quando houver ambiguidade, contradição, omissão ou obscuridade. ${ }^{3}$

\footnotetext{
${ }^{3}$ BRASIL. Decreto no 737 de 25 de Novembro de 1850. Palácio do Rio de Janeiro, RJ: Presidência da República Casa Civil Subchefia para Assuntos Jurídicos, artigo 641.
} 
Atualmente, os embargos de declaração são a modalidade apta a possibilitar um melhor esclarecimento da decisão embargada. Tem por característica a busca de uma decisão plena, harmônica e clara, de modo que a torne compreensível e por consequência, eficaz, no momento da execução do julgado.

Para a utilização dos embargos de declaração são necessários alguns requisitos, tais como apontar a existência de erro material, contradição, omissão ou obscuridade sobre o qual o magistrado ou o colegiado deveria ter pronunciado. Por esse aspecto, o presente recurso denota uma condição de fundamentação vinculada. ${ }^{4}$

Cabe então a quem esteja manejando o recurso e em suas razões apontar se há omissão, erro material, obscuridade ou contradição na decisão embargada. Caso não se faça os embargos não são conhecidos. Dessa forma, entende-se que não é cabível a oposição de embargos de declaração sem apontar ao menos um desses quatro requisitos, pleiteando tão somente a reconsideração da decisão proferida.

\subsection{REQUISITOS SUBJETIVOS DE INTERPOSIÇÃO}

Não raras as situações, em pronunciamentos judiciais pode-se conter erros materiais. Quando ocorrem há apenas duas alternativas para saná-los: correção de ofício pelo julgador ou provocação das partes.

Portanto, permite-se "que o juiz possa corrigir evidentes e inequívocos enganos involuntários ou inconscientes, retratados em discrepâncias entre o que se quis afirmar e o que restou consignado no texto da decisão". ${ }^{5}$ Sendo assim, o erro material na decisão proferida é visível quando "[...] o que está escrito na decisão não corresponde à intenção do juiz, desde que isso seja perceptível por qualquer homem médio". 6

Caso uma das partes identifique o erro material constante na decisão, poderá interpor então os embargos de declaração (art. 1022, inciso III, Código de Processo Civil de 2015), a fim de que corrija o erro apontado.

\footnotetext{
${ }^{4}$ DIDIER JUNIOR, Fredie; CUNHA, Leonardo Carneiro. Curso de direito processual civil nos tribunais: recurso, ações de competência originária de tribunal e querela nullitatis, incidente de competência originária de tribunal. 13 ed. reform. Salvador: Ed. JusPodivm, 2016, p. 248.

${ }^{5}$ DIDIER JUNIOR, Fredie; CUNHA, Leonardo Carneiro. Curso de direito processual civil nos tribunais: recurso, ações de competência originária de tribunal e querela nullitatis, incidente de competência originária de tribunal. 13 ed. reform. Salvador: Ed. JusPodivm, 2016, p. 249.

${ }^{6}$ WAMBIER, Teresa Arruda Alvim. Omissão judicial e Embargos de declaração. São Paulo: RT, 2005, n. 1.6, p. 95.
} 
Sobre a contradição cumpre dizer que, como base de julgamento, exige-se da decisão judicial uma coerência lógica, de modo que a exposição da fundamentação esteja consonante com a decisão final e os fatos. Caso não haja essa congruência, o recurso cabível para sanar tal contradição é justamente os embargos de declaração (art. 1.022, inciso I, Código de Processo Civil de 2015).

Nessa toada, tem-se por adequado dizer que a decisão é contraditória quando há discrepância entre o fundamentado e o decidido, ou, ainda, vale-se da exímia definição: "A decisão é, enfim, contraditória quando traz proposições entre si inconciliáveis. O principal exemplo é a existência de contradição entre a fundamentação e a decisão". ${ }^{7}$

Seguindo por essa lógica, caso se observe a contradição entre o fundamentado e o decidido, a decisão deverá ser revista pelo julgador, alterando o dispositivo e sanando a contradição, esse é também o entendimento da doutrina:

E, havendo contradição entre a fundamentação e o dispositivo, ao menos uma dessas partes do pronunciamento terá de ser revista pelo julgador: ou mantém ele o dispositivo, retificando a fundamentação, para que ela esclareça ao destinatário o raciocínio desenvolvido e os elementos que formaram a convicção do magistrado; ou, caso entenda que a fundamentação está correta, e que o equívoco se deu quando da redação do dispositivo, deve alterar este último, adequando-o à fundamentação mantida; ou, ainda, pode entender que, para a solução da contradição, a decisão merece revisão mais ampla, com a necessidade de modificações dos fundamentos e do dispositivo. ${ }^{8}$

Por esse motivo, como consequência direta da oposição dos embargos de declaração para esclarecer a contradição, pode-se ocorrer, dependendo do caso, a modificação da decisão, conhecido com o efeito infringente ou modificativo, que será tratado com maior atenção no capítulo seguinte.

Diante do entrave processual, a parte autora apresentará seus argumentos fáticos e o que entende ser seu de direito, e a parte ré impugnará cada ponto e discorrerá sobre eles, se for o caso. Há então, a

\footnotetext{
${ }^{7}$ DIDIER JUNIOR, Fredie; CUNHA, Leonardo Carneiro. Curso de direito processual civil nos tribunais, recurso, ações de competência originária de tribunal e querela nullitatis, incidente de competência originária de tribunal. 13 ed. reform. Salvador: Ed. JusPodivm, 2016, p. 251.

8 FERNANDES, Luís Eduardo Simardi. Embargos de declaração: efeitos infringentes, prequestionamento e outros aspectos polêmicos. 3. ed. rev. atual. e ampl. São Paulo: Editora Revista dos Tribunais, 2012, p. 98.
} 
obrigatoriedade de o juiz examinar todas essas questões, salvo condição de acolhimento de preliminares ou fatores básicos peremptórios impeditivos, modificativos ou extintivos do direito do autor.

Por outro lado, há-se o dever de fundamentação da decisão, com espeque ao art. 93, IX, da Constituição Federal de 1988, exigindo que a decisão judicial não contenha omissões. Caso ocorra, poderá a parte interessada valer-se do recurso de embargos de declaração, o qual busca suprir questões ou pontos que não foram observados.

Por esse aspecto, considera-se omissa a decisão que:

[...] não se manifestar: a) sobre um pedido de tutela jurisdicional; b) sobre fundamentos e argumentos relevantes lançados pelas partes (art. $\left.489, \S 1^{\circ}, \mathrm{IV}\right)$; c) sobre questões apreciáveis de oficio pelo magistrado, tenham ou não tenham sido suscitadas pela parte tenham ou não tenham sido suscitadas pela parte. ${ }^{9}$

Sendo assim, se a decisão não apresentar argumentos sobre alguns dos itens supracitados, entre outros possíveis, considerar-se-á omissa, para fins alicerce de embargos de declaração.

Em se tratando da obscuridade, a decisão judicial tem como um de seus requisitos a necessidade de se primar pela clareza e facilidade de compreensão. A decisão é obscura quando seu conteúdo é incompreensível ou confuso.

Quando a decisão não possui clareza, cabem embargos de declaração, pleiteando em nível recursal a elucidação almejada. Para melhor entendimento sobre o pronunciamento pautado em obscuridade, Fredie Didier Junior e Leonardo Carneiro Cunha expõe o seguinte pensamento: "A decisão obscura é aquela que não ostenta clareza. A decisão que não é clara desatende à exigência constitucional da fundamentação. Quando o juiz ou tribunal não é preciso [...] está a proferir decisão obscura, que merece ser esclarecida."10

Nesse mesmo sentido destaca Luís Eduardo Simardi Fernandes:

A obscuridade, em regra, é fruto de duas situações distintas. Pode acontecer de o juiz estar absolutamente certo e seguro daquilo que

\footnotetext{
${ }^{9}$ DIDIER JUNIOR, Fredie; CUNHA, Leonardo Carneiro. Curso de direito processual civil nos tribunais: recurso, ações de competência originária de tribunal e querela nullitatis, incidente de competência originária de tribunal. 13. ed. reform. Salvador: Ed. JusPodivm, 2016, p. 251.

${ }^{10}$ DIDIER JUNIOR, Fredie; CUNHA, Leonardo Carneiro. Curso de direito processual civil nos tribunais: recurso, ações de competência originária de tribunal e querela nullitatis, incidente de competência originária de tribunal. 13 ed. reform. Salvador: Ed. JusPodivm, 2016, p. 256.
} 
vai decidir, tendo em mente todo o raciocínio lógico que norteará sua decisão, mas acabar por redigir o pronunciamento de difícil compreensão, deixando dúvidas sobre o que pretendeu efetivamente dizer. [...] Outra hipótese é aquela em que a decisão se mostra obscura porque o próprio juiz, no seu íntimo, estava pouco seguro do que decidir. Ou seja, hesitante, acabou por transferir essa hesitação para a decisão, ocasionando a obscuridade. $^{11}$

Importante se faz, dessa forma, quando da oposição do recurso de Embargos de declaração, que este aponte necessariamente em seu escopo onde se encontra tal obscuridade, para que o magistrado aprecie os Embargos e, caso concorde, corrija a decisão proferida.

\subsection{PRONUNCIAMENTOS RECORRÍVEIS}

Previsto no Código de Processo Civil de 2015, art. 1.022, os Embargos de declaração são oponíveis contra qualquer decisão judicial, incluindo as do Juizados Especiais e Turmas Recursais de acordo com os artigos 1064 e 1066 da lei processual em vigor, prestando-se como já antes dito, para: I - esclarecer obscuridade ou eliminar contradição; II - suprir omissão de ponto ou questão sobre o qual devia se pronunciar o juiz de ofício ou a requerimento; III - corrigir erro material. ${ }^{12}$ Nesse sentido, os Embargos de Declaração talvez seja o recurso com maior amplitude quando se refere ao seu cabimento.

No tocante a esta vasta aplicabilidade, Daniel Amorim Assumpção Neves descreve:

O entendimento é incontestável, porque não há nenhum sentido permitir que pronunciamentos omissos, contraditórios ou obscuros não posam ser impugnados pelas partes que pretendem afastar tais vícios no caso concreto. Por vezes, a incompreensão de um pronunciamento judicial pode inclusive impedi-lo de atingir sua finalidade, além de uma decisão omissa ser óbvia denegação da atividade jurisdicional, o que em nenhuma hipótese pode ser aceito. $^{13}$

\footnotetext{
11 FERNANDES, Luís Eduardo Simardi. Embargos de declaração: efeitos infringentes, prequestionamento e outros aspectos polêmicos. 3. ed. rev. atual. e ampl. São Paulo: Editora Revista dos Tribunais, 2012, p. 94.

${ }^{12}$ BRASIL. Código de processo civil: Lei n.13.105, de março de 2015. Publicador: Brasília: Senado Federal, Secretaria de Editoração e Publicações, 2015, art. 1.022.

${ }^{13}$ NEVES, Daniel Amorim Assumpção. Manual de direito processual civil. 8. ed. - Salvador: Ed. JusPodivm, 2016, p. 2809.
} 
De mais a mais, tem-se por certo que os Embargos de Declaração - especialmente com o Código de Processo Civil de 2015 - passa a ter uma abrangência mais ampla, sendo oponível, de acordo com o art. 1.022, sobre toda e qualquer decisão judicial que contenha omissão, contradição, obscuridade ou erro material.

\subsection{PROCEDIMENTO}

Os Embargos de Declaração devem ser interpostos pela modalidade escrita, dentro de um prazo de cinco dias contados da leitura da intimação do decisório. E quanto a sua forma, há a necessidade de fundamentação, limitando-se no que pertine as matérias alegáveis (recurso com fundamentação vinculada) e, ainda, deve conter um pedido, seja de integração, aclaramento, ou, em alguns casos, da reforma da decisão. ${ }^{14} \mathrm{~A}$ exigência de indicação dessas matérias alegáveis se dá com espeque ao art. 1.023, caput, do Código de Processo Civil de 2015.

Essa petição recursal escrita deverá indicar omissão, obscuridade, contradição ou o erro material que pretende corrigir. Caso não o faça, culminará em sua inadmissibilidade, conforme explicação de Alexandre de Freitas Câmara: "A não indicação do ponto equivocado, obscuro, contraditório ou omisso na peça de interposição do recurso implica sua inadmissibilidade, sendo então o caso de não se conhecer do recurso". ${ }^{15}$

Em complemento, cumpro observar-se que, opostos os Embargos de declaração, sendo ele unipessoal, a competência para seu julgamento é do magistrado que proferiu a decisão. ${ }^{16}$

Por fim, à luz do artigo 1.024, $\$ 3^{\circ}$ do Código de Processo Civil de 2015 e do princípio da fungibilidade recursal, caso os Embargos sejam opostos erroneamente, admite-se a sua conversão pelo recurso denominado de Agravo Interno.

\subsection{EFEITOS DOS EMBARGOS DE DECLARAÇÃO}

\footnotetext{
${ }^{14}$ Ibidem, p. 2815.

${ }^{15}$ CÂMARA, Alexandre Freitas. O novo processo civil brasileiro. 2. ed. São Paulo: Atlas, 2016, p. 533.

${ }^{16}$ PINHO, Humberto Dalla Bernardina de. Direito processual civil contemporâneo. vol. 2: processo de conhecimento, cautelar, execução e procedimentos especiais. 3. ed. São Paulo. Saraiva, 2016, p. 907.
} 
O efeito devolutivo, comum na maioria dos recursos, é o efeito que devolve a matéria atacada ao juiz prolator da decisão, buscando seu reexame.

Pode ser definido também como: "O efeito devolutivo provoca a remessa da matéria atacada para reapreciação por órgão jurisdicional de grau hierárquico superior, dito ad quem, em relação ao que proferiu a decisão recorrida"17. Mantendo essa linha de raciocínio, José Miguel Garcia Medina entende o efeito devolutivo dos Embargos como sendo: "[...] Aquele em virtude do qual o conhecimento da matéria é devolvido ao órgão judicante, seja superior àquele do qual emanou a decisão, seja ao próprio órgão prolator da decisão". ${ }^{18}$

De mais a mais, caso haja devolução e reexame da decisão, ela não pode se tornar definitiva, isso porque, o efeito devolutivo obsta a coisa julgada na matéria recorrida. ${ }^{19} \mathrm{Na}$ hipótese de inexistir tal efeito na oposição de embargos declaratórios, seu exame não impediria a preclusão da decisão embargada.

A ocorrência de tal efeito é discutível, tendo-se em vista que não há a interação entre órgãos julgadores onde um devolve a jurisdição ou poder de julgar para o outro, sendo que no caso de Embargos de Declaração o próprio juiz que proferiu a decisão é o que a analisará por meio de tal recurso. Porém, é possível a interpretação de que o efeito devolutivo neste caso seria aplicado no sentido de devolver a decisão para correção, o que não é considerado o funcionamento padrão do efeito devolutivo de recursos.

O efeito suspensivo, também chamado de obstativo, é aquele que impede a produção dos efeitos da decisão, obstando a conclusão da lide até o julgamento do recurso.

De acordo com o que dispõe o art. 1.026 do Código de Processo Civil de 2015, os embargos não possuem tal efeito, ajustando-se aos preceitos do art. 995 do mesmo diploma legal, que demonstra que os recursos não possuem, na sua forma natural, o efeito suspensivo, salvo quando requerido pela parte que o interpor e assim for possível a aplicação.

\footnotetext{
${ }^{17}$ FERNANDES, Luís Eduardo Simardi. Embargos de declaração: efeitos infringentes, prequestionamento e outros aspectos polêmicos. 3. ed. rev. atual. e ampl. São Paulo: Editora Revista dos Tribunais, 2012, p. 68

${ }^{18}$ MEDINA, José Miguel Garcia, WAMBIER, Teresa Arruda Alvim. Recursos e ações autônomas de impugnação. 3. ed. rev. E atual. São Paulo: Editora Revista dos Tribunais, 2013, v. 2, p. 101.

${ }^{19}$ Ibidem, p. 102.
} 
Dessa forma, esse efeito não é automático ${ }^{20}$, o que demonstra que se trata aqui de um recurso que não possui o condão de suspender efeitos imediatos de decisões judiciais.

Isto posto, pacifica-se o entendimento de que os embargos de declaração não possuem efeito suspensivo espontâneo, podendo ser requerido pela parte que o opuser. Caso acolhido pelo Tribunal, ou juiz singular, os Embargos de Declaração obstarão os efeitos da decisão e impedirão a coisa julgada até que se resolva-o.

Ainda, deve-se destacar a existência do efeito interruptivo dos prazos recursais, visto que, a interposição do recurso objeto deste trabalho para e zera a contagem do prazo para interposição dos demais recursos cabíveis da eventual decisão embargada, passando a correr tal prazo novamente deste o primeiro dia de contagem, a partir da leitura da intimação da decisão que julga os embargos declaratórios, viabilizando assim a interposição do outro recurso respectivo.

Sabe-se ainda, que os Embargos de Declaração possuem outro efeito, o infringente (ou modificativo), sendo que tal efeito será tratado com maior atenção no próximo capítulo.

\section{O EFEITO MODIFICATIVO DOS EMBARGOS DE DECLARAÇÃO}

O recurso embargos de declaração, além dos efeitos comumente presentes, quais sejam: o efeito interruptivo, o suspensivo e o efeito devolutivo (contraditoriamente), possui também o chamado "efeito infringente".

Não se sabe, ao certo, desde quando a jurisprudência acolhe essa modalidade infringente dos embargos aclaratórios. Miguel Seabra Fagundes, em sua busca para datar os primeiros Embargos com efeito infringente no país, trouxe em obra dedicada a este recurso, decisão do Tribunal de Justiça do Estado de São Paulo, da 2a Câmara Cível, em 07 de junho do ano de 1929, onde o órgão julgou de forma equivocada pela intempestividade do agravo interposto. $\mathrm{O}$ advogado agravante ao perceber o erro material que havia sido cometido, interpôs Embargos de Declaração

${ }^{20}$ DIDIER JUNIOR, Fredie; CUNHA, Leonardo Carneiro. Curso de direito processual civil nos tribunais: recurso, ações de competência originária de tribunal e querela nullitatis, incidente de competência originária de tribunal. 13. ed. reform. Salvador: Ed. JusPodivm, 2016, p. 272. 
com o objetivo de sanar o vício. Tendo razão o embargante, o juiz modificaram a decisão, reconhecendo que os embargos eram, na realidade, tempestivos. ${ }^{21}$

Apesar do efeito modificativo dos embargos de declaração ser tratado expressamente somente no Código de Processo Civil de 2015, desde o final da década de 20 já se tem notícias de decisões com esse efeito.

Nesse mesmo sentido, o Supremo Tribunal de Federal, em seu regimento interno, mais precisamente no art. 338, assim definiu:

\footnotetext{
Se os embargos forem recebidos, a nova decisão se limitará a corrigir a inexatidão, ou a sanar a obscuridade, dúvida, omissão ou contradição, salvo se algum outro aspecto da causa tiver de ser apreciado como consequência necessária. ${ }^{22}$
}

Além do regimento interno, o Supremo Tribunal de Federal possui uma corrente decisória que vem permitindo, em alguns casos, o efeito modificativo dos embargos de declaração desde antes do advento do próprio Código de Processo Civil de 2015.

À luz do Código de Processo Civil de 1973, dizia-se que os embargos não poderiam modificar a decisão, isso porque, ele possuía apenas a função de sanar quaisquer vícios contidos no decisum.

Durante toda a vigência do código, houve discussões sobre a possibilidade de efeito modificativo de tal recurso, sendo que parte da doutrina entendia que os Embargos não possibilitavam o reexame da decisão, apenas a correção desta.

A outra parte entendia que o efeito infringente era possível, desde que os embargos fossem manejados utilizando-se dos quatro requisitos: esclarecer obscuridade, eliminar contradição, suprir omissão ou corrigir erro material.

Percebia-se então, alguns julgados que contemplavam essa possibilidade de modificar a decisão embargada, porém, para que fosse admitida tal reforma, se fazia necessário observar os quatro requisitos supracitados de modo que a modificação fosse uma mera consequência do recurso em questão.

\footnotetext{
${ }^{21}$ FAGUNDES, Miguel Seabra. Dos embargos de declaração. Litis: revista trimestral de direito processual, 5-13, 1976, p. 11. Acesso em: 14 out. 2017.

${ }^{22}$ BRASIL. Supremo Tribunal Federal (STF). Regimento Interno. Consolidado e atualizado até maio de 2002 por Eugênia Vitória Ribas. Brasília: STF, 2016.
} 
A título de exemplo, a corrente minoritária que entendia pela não possibilidade do efeito modificativo, conforme decisão do Tribunal de Justiça do Estado do Rio Grande do Sul: "EMBARGOS DE DECLARAÇÃO. ERRO MATERIAL PASSÍVEL DE CORREÇÃO, MAS SEM MODIFICAÇÃO DO JULGADO." 23

Seguindo na mesma linha de pensamento, o Tribunal de Justiça do Distrito Federal também decidiu:

\begin{abstract}
PROCESSUAL CIVIL. EMBARGOS DE DECLARAÇÃO. ERRO MATERIAL. INEXISTÊNCIA. ALTERAÇÃO DO JULGADO. IMPOSSIBILIDADE. INCONFORMISMO. REJEIÇÃO.

1. O artigo 463, I, do CPC autoriza a modificação do Julgado quando se verifica singelo equívoco por ocasião do julgamento, cuja correção não transcende os lindes da mera inexatidão ou erro material.2. A rejeição de tese recursal não configura a existência de erro material passível de correção e alteração do Acórdão.3. O inconformismo da parte com o resultado do julgamento deverá ser materializado por meio de recurso adequado, afastados os embargos declaratórios, cujo objetivo é tão somente o de depurar meras imperfeições no Julgado, in casu, inexistentes. 4. Embargos de declaração desprovidos. Unânime. ${ }^{24}$
\end{abstract}

Cumpre observar que decisões eram prolatadas em sentido de não possibilidade do efeito modificativo diante da inexistência de reflexos que causassem modificação no caráter decisório, e por vezes simplesmente negavam efeitos infringentes em sentido genérico, mesmo diante de necessária modificação do decisum frente a alguma alteração advinda dos quesitos a que se prestam os Embargos de Declaração a atacar.

Após muito debate e nenhum consenso sobre essa particularidade do recurso dos embargos de declaração, o Código de Processo Civil de 2015 entendeu por positivar a questão e findar qualquer controvérsia sobre o efeito modificativo dos embargos de declaração. Como anteriormente tratava-se de uma construção jurisprudencial e doutrinária, agora, com o

\footnotetext{
${ }^{23}$ BRASIL. Tribunal de Justiça do Estado do Rio Grande do Sul (TJ-RS). Recurso Cível $\mathrm{n}^{\circ}$ 71000595124. Relatora: Mylene Maria Michel. Diário da Justiça do dia 02/05/2005. Disponível em: $<$ https://tj-rs.jusbrasil.com.br/jurisprudencia/7875748/recurso-civel-71000595124-rs $>$ acesso em: 08 out. 2017.

24 TJ-DF. Embargos de declaração no Agravo de instrumento $n^{o}$ EMD1 201400200796971.Terceira Turma Cível. Relator: Getúlio de Moraes Oliveira. Brasília, DF, 24 de setembro de 2014. Diário da Justiça do Dia 02/10/2014, p. 98. Disponível em: <https://tj-df.jusbrasil.co m.br/jurisprudencia/311502517/Embargos-de-declaracao-no-a-agravo-de-instrumento-emd1-

201400200796971-agravo-de-instrumento> Acesso em: 24 out. 2017.
} 
novo diploma processual, caracteriza-se como uma norma positivada, porém ainda com peculiaridades.

$\mathrm{O}$ art. 1.023, $\S 2^{\circ}$ do mesmo diploma legal, possibilitou esse efeito infringente, pacificando o entendimento de que a utilização dos Embargos de Declaração poderá culminar na modificação da decisão embargada. Traz-se, então, a íntegra do referido artigo:

Art. 1.023. Os embargos serão opostos, no prazo de 5 (cinco) dias, em petição dirigida ao juiz, com indicação do erro, obscuridade, contradição ou omissão, e não se sujeitam a preparo.

$\S 1^{\circ}$ Aplica-se aos embargos de declaração o art. 229.

$\S 2^{\circ} \mathrm{O}$ juiz intimará o embargado para, querendo, manifestar-se, no prazo de 5 (cinco) dias, sobre os embargos opostos, caso seu eventual acolhimento implique a modificação da decisão embargada. ${ }^{25}$

E, ainda nesse sentido, o art. 1.024, $\S 4^{\circ}$ também possibilita essa modificação da decisão embargada:

Art. 1.024. O juiz julgará os embargos em 5 (cinco) dias.

$\S 1^{\circ}$ Nos tribunais, o relator apresentará os embargos em mesa na sessão subsequente, proferindo voto, e, não havendo julgamento nessa sessão, será o recurso incluído em pauta automaticamente.

$\S 2^{\circ}$ Quando os embargos de declaração forem opostos contra decisão de relator ou outra decisão unipessoal proferida em tribunal, o órgão prolator da decisão embargada decidi-los-á monocraticamente.

$\S 3^{\circ} \mathrm{O}$ órgão julgador conhecerá dos embargos de declaração como agravo interno se entender ser este o recurso cabível, desde que determine previamente a intimação do recorrente para, no prazo de 5 (cinco) dias, complementar as razões recursais, de modo a ajustálas às exigências do art. $1.021, \S 1^{\circ}$.

$\S 4^{\circ}$ Caso o acolhimento dos embargos de declaração implique modificação da decisão embargada, o embargado que já tiver interposto outro recurso contra a decisão originária tem o direito de complementar ou alterar suas razões, nos exatos limites da modificação, no prazo de 15 (quinze) dias, contado da intimação da decisão dos embargos de declaração.

$\S 5^{\circ} \mathrm{Se}$ os embargos de declaração forem rejeitados ou não alterarem a conclusão do julgamento anterior, o recurso interposto pela outra parte antes da publicação do julgamento dos embargos de declaração será processado e julgado independentemente de ratificação. ${ }^{26}$

Afirma-se, em determinadas situações, a possibilidade de efeito infringente dos embargos de declaração, hipótese em que "o embargante

\footnotetext{
${ }^{25}$ BRASIL. Código de Processo Civil. Lei no 13.105, de 16 de março de 2015.

${ }^{26}$ Ide BRASIL. Código de Processo Civil. Lei no 13.105, de 16 de março de 2015.
} 
não pode ter como pretensão pedir a infringência do julgado, isto é, a reforma da decisão embargada. A infringência ocorrerá como consequência necessária do julgamento dos Embargos". ${ }^{27}$

Alerta-se que a função do recurso de embargos de declaração não é, e nunca foi, modificar o conteúdo das decisões impugnadas. ${ }^{28}$ Sua utilização sempre foi corrigir, sanar, esclarecer. O que pode ocorrer, é o que já fora mencionado anteriormente, da utilização dos embargos culminar na alteração de algum ponto do que foi decidido. Nesses casos, o mais frequente é quando se busca sanar uma omissão, já que nesse caso a decisão de Embargos será além do que fora decidido anteriormente, o que, por lógica, modificaria a decisão. ${ }^{29}$

Pode-se dizer que os embargos de declaração têm por função típica "consertar" a decisão embargada, sem reexame da matéria. Contudo, em alguns casos, esse recurso pode extrapolar sua função habitual, gerando a necessidade de alterar o caminho perseguido pelo que fora decidido, seja em sua integralidade ou em apenas algum quesito.

Dessa forma, o Código de Processo Civil de 2015 abriu a possibilidade de efeito modificativo positivadamente, fato que já vinha obtendo resultados nas decisões recentes nos Tribunais Regionais, como por exemplo na decisão de Embargos de Declaração proferida pela Quarta Turma Recursal Cível do Rio Grande do Sul:

EMBARGOS DE DECLARAÇÃO. ACOLHIMENTO DOS EMBARGOS COM EFEITOS INFRINGENTES, A FIM DE AFASTAR A CONDENAÇÃO IMPOSTA NO ACÓRDÃO, ANTE A AUSÊNCIA DE PEDIDO EXPRESSO DE LUCROS CESSANTES. SENTENÇA CONFIRMADA NOS TERMOS DO ART. 46 DA LEI 9.099 /95. EMBARGOS DE DECLARAÇÃO ACOLHIDOS COM EFEITOS MODIFICATIVOS. ${ }^{30}$

Perseguindo tal seara, a Segunda Turma Recursal do Tribunal de Justiça do Estado do Rio Grande do Sul também decidiu:

\footnotetext{
${ }^{27}$ PINHO, Humberto Dalla Bernardina de. Direito processual civil contemporâneo: processo de conhecimento, cautelar, execução e procedimentos especiais. vol. 2. 3. ed. São Paulo. Saraiva, 2016, p. 906

${ }^{28}$ NEVES, Daniel Amorim Assumpção. Manual de direito processual civil. 9. ed. - Salvador: Ed. JusPodivm, 2017, p. 1.708.

${ }^{29}$ Idem.

${ }^{30}$ BRASIL. RJ-RS. Embargos de declaração $N^{o} 71006828719$. Quarta Turma Recursal Cível, Turmas Recursais, Relator: Gisele Anne Vieira de Azambuja, Julgado em 17/08/2017. Disponível em: <https://tj-rs.jusbrasil.com.br/jurisprudencia/491284497/Embargos-de-declaracao-ed-71006828719rs> Acesso em: 24 out. 2017.
} 
EMBARGOS DE DECLARAÇÃO. ACÓRDÃO QUE PARTIU DE PREMISSA EQUIVOCADA. VALOR COBRADO DA AUTORA E POR ELA PAGO CUJA ORIGEM NÃO RESTOU DEMONSTRADA PELA PARTE DEMANDADA, ÔNUS QUE A ESTA CABIA. PAGAMENTO INDEVIDO. DEVER DE DEVOLUÇÃO, NA FORMA DOBRADA. ART. 42, PARÁGRAFO ÚNICO, DO CDC. RECURSO PROVIDO. EMBARGOS DE DECLARAÇÃO ACOLHIDOS, COM EFEITOS MODIFICATIVOS. ${ }^{31}$

Assim, os embargos de declaração podem ter o efeito modificativo, alterando substancialmente a decisão embargada, de modo a propiciar uma decisão mais acertada. O Código de Processo Civil de 2015 acabou facilitando e positivando esse efeito, gerando decisões que seguem esse raciocínio, conforme demonstrado acima. ${ }^{32}$

Em outras palavras, fora positivado o entendimento que era anteriormente aplicado jurisprudencialmente na vigência do Código de Processo Civil de 1973.

Essa mudança no entendimento e a posterior positivação, gerando a possibilidade do efeito infringente, em pouco tempo de vigor do novo diploma processual, trouxe uma mudança substancial para os operadores do direito no que concernem os Embargos de Declaração.

Ainda, com o novo Código, diversos doutrinadores vêm se manifestando com a concordância do efeito modificativo dos Embargos, como por exemplo, o que compreende Daniel Amorim Assumpção Neves nas palavras abaixo:

Ocorre, entretanto, que em algumas hipóteses de saneamento de contradição e omissão - muito mais frequente na segunda hipótese - o provimento dos embargos de declaração, com o consequente saneamento do vício, poderá ensejar a modificação do conteúdo da decisão recorrida. ${ }^{33}$

\footnotetext{
${ }^{31}$ BRASIL. Embargos de declaração $N^{o} 71006211916$. Segunda Turma Recursal Cível, Turmas Recursais, Relator: Roberto Behrensdorf Gomes da Silva, Julgado em 28/09/2016). Segunda Turma Recursal Cível Diário da Justiça do dia 03/10/2016 - 3/10/2016 embargos de declaração. Disponível em: $<$ https://tj-rs.jusbrasil.com.br/jurisprudencia/390631023/Embargos-de-declaracao-ed71006211916-rs> Acesso em: 24 out. 2017.

${ }_{32}$ MARINONI, Luiz Guilherme; ARENHART, Sérgio Cruz; MITIDIERO, Daniel. Novo Código de Processo Civil comentado. 3. ed. rev., atual, e ampl. São Paulo. Editora Revista dos Tribunais, 2017, p. 1102.

${ }^{33}$ NEVES, Daniel Amorim Assumpção. Manual de direito processual civil. 8. ed. Salvador: Ed. JusPodivm, 2016.p. 2827
} 


\section{Ainda, coadunando com esta linha de pensamento Luís Eduardo Simardi Fernandes preleciona conforme segue:}

[...] E não temos receio em afirmar que os embargos de declaração podem, sem dúvida alguma, apresentar o efeito de modificar a decisão embargada, na sua essência. [...] Acreditamos que esses efeitos modificativos haverão de se fazer presentes não apenas em casos excepcionais [...] mas sim sempre que essa modificação do julgado for consequência, natural e necessária, do conhecimento e julgamento do recurso sob exame. ${ }^{34}$

\section{Em complemento importante, as colocações de Alexandre Freitas Câmara que ressalta:}

Pode acontecer de os embargos de declaração veicularem pretensão que, caso acolhida, acarrete a modificação da decisão embargada. Tem-se aí o que se costuma chamar de embargos de declaração com efeitos modificativos (também chamados embargos de declaração com efeitos infringentes). ${ }^{35}$

Nota-se que os autores supracitados se manifestam na mesma corrente de que existe hoje claramente o efeito modificativo dos embargos de declaração, e que tal efeito deverá surgir de uma oposição natural dos embargos aclaratórios, ou seja, a infringência deverá ser consequência.

Não poderia ser diferente, já que o Código de Processo Civil atual trouxe em seu bojo a positivação e possibilidade dos efeitos modificativos. Humberto Dalla Bernardina de Pinho se posicionou da seguinte forma:

Os embargos podem ter, contudo, efeitos infringentes, quando o suprimento da omissão, contradição, obscuridade ou erro material ocasiona modificação no julgamento do pronunciamento judicial. Nessa hipótese, o embargante não pode ter como pretensão pedir a infringência do julgado, isto é, a reformar da decisão embargada. A infringência ocorrerá como consequência necessária do julgamento dos Embargos. ${ }^{36}$

Por fim, complementando essa linha de raciocínio, Fredie Didier Junior e Leonardo Carneiro da Cunha explanam:

\footnotetext{
34 FERNANDES, Luís Eduardo Simardi. Embargos de declaração: efeitos infringentes, prequestionamento e outros aspectos polêmicos. 3. ed. rev. atual. e ampl. São Paulo: Editora Revista dos Tribunais, 2012. p. 191

${ }^{35}$ CÂMARA, Alexandre Freitas. O novo processo civil brasileiro. 2. ed. São Paulo: Atlas, 2016.p. 532.

${ }^{36}$ PINHO, Humberto Dalla Bernardina de. Direito processual civil contemporâneo. vol. 2: processo de conhecimento, cautelar, execução e procedimentos especiais. 3. ed. São Paulo. Saraiva, 2016, p. 906
} 
Acontece, porém, que do julgamento dos embargos pode advir alteração da decisão embargada. De fato, ao suprir uma omissão, eliminar uma contradição, esclarecer uma obscuridade ou corrigir um erro material, o juiz ou tribunal poderá, consequentemente, alterar a decisão embargada. Nesse caso, diz-se que os embargos têm efeitos modificativos ou infringentes. ${ }^{37}$

Nota-se que a aceitação do efeito modificativo é vasta, todavia, cumpre ressaltar, que os mesmos artigos citados preveem a necessidade de contrarrazões, quando, da oposição dos Embargos de Declaração, resultar modificação da decisão (art. 1.024, \$4 ${ }^{\circ}$ Código de Processo Civil de 2015). "Isso se dará, no entanto, nos exatos e precisos limites da modificação causada pelo acolhimento dos Embargos, e deverá ser feito em quinze dias $[\ldots]^{\prime \prime} \cdot 38$

Dessa maneira, restou demonstrado que os doutrinadores, bem como a maciça jurisprudência coadunam com o entendimento da possibilidade dos efeitos modificativos nos casos em que os embargos de declaração forem propostos seguindo seu objeto natural, até por isso, entende-se que com o passar do tempo esse instituto será assentado pacificamente no ordenamento jurídico, alterando os limites da interposição do recurso de embargos de declaração.

\subsection{NECESSIDADE DE CONTRARRAZÕES}

Normalmente, após opostos embargos de declaração, ocorrerá o julgamento em cinco dias e caso opostos em tribunal, será apresentado na próxima sessão, ao qual o relator proferirá seu voto. ${ }^{39}$

Contudo, quando se trata do efeito modificativo, se faz imperioso possibilitar o contraditório, intimando a parte adversa para apresentação, caso queira, de contrarrazões. Essa medida é utilizada para que não pairem dúvidas sobre o julgamento, e ainda, para que não ocorram "decisões surpresa".

Nesse diapasão, esses dispositivos supracitados concretiza o princípio do contraditório e da ampla defesa, estendendo o tempo de

\footnotetext{
${ }^{37}$ DIDIER JUNIOR, Fredie; CUNHA, Leonardo Carneiro. Curso de direito processual civil nos tribunais: recurso, ações de competência originária de tribunal e querela nullitatis, incidente de competência originária de tribunal. 13. ed. reform. Salvador: Ed. JusPodivm, 2016, p. 273.

${ }^{38}$ PINHO, Humberto Dalla Bernardina de. Direito processual civil contemporâneo. vol. 2: processo de conhecimento, cautelar, execução e procedimentos especiais. 3. ed. São Paulo. Saraiva, 2016, p. 907

${ }^{39}$ ASSIS, Araken de. Manual dos recursos. 1.ed. São Paulo: Editora Revista dos Tribunais, 2016, p. 575 .
} 
resposta decisória recursal. Nessa hipótese, caso não haja intimação da parte adversa para contrarrazoar os embargos de declaração que modificaram a decisão embargada, haverá nulidade da decisão. ${ }^{40}$

\subsection{COMPLEMENTARIDADE DO RECURSO INTERPOSTO}

Aludindo o $\S 4^{\circ}$ do art. 1.024 do Código de Processo Civil de 2015, traz a regra de complementação do recurso interposto pelo embargado que tiver insurgido sobre a decisão que foi modificada via embargos de declaração. ${ }^{41} \mathrm{O}$ teor do parágrafo supracitado expõe: "Caso o acolhimento dos embargos de declaração implique modificação da decisão embargada, o embargado que já tiver interposto recurso contra a decisão originária tem o direito de complementar ou alterar suas razões [...]”.

Por esse aspecto, no tocante ao recurso oposto pela parte adversa ter sido anterior a modificação da decisão via embargos de declaração, este recorrente poderá complementar tal recurso, de modo que é facultada a ele essa complementação/alteração, mas, todavia, não poderá interpor um novo recurso, salvo raríssimos casos em que a decisão modificativa alterar consubstancialmente a natureza do pronunciamento judicial. ${ }^{42}$

Fredie Didier Junior entende que nessa regra de complementaridade do recurso interposto pela parte adversa, há clara e objetiva intenção de se garantir o princípio do contraditório:

Há aí uma regra que concretiza o princípio do contraditório, garantindo ao recorrente o direito ao aditamento do recurso já interposto, para que possa impugnar a decisão em seus termos mais atuais, após ter sido alterada pelo acolhimento dos embargos de declaração anteriormente opostos. Se o provimento dos embargos de declaração implicar modificação do julgado, pode a parte, que interpusera o recurso, aditá-lo, para impugnar a parcela da decisão que foi modificada. E só. Não é o caso de interpor outro recurso; não pode recorrer de novo. Poderá, em novo prazo de quinze dias,

${ }^{40}$ DIDIER JUNIOR, Fredie; CUNHA, Leonardo Carneiro. Curso de direito processual civil nos tribunais: recurso, ações de competência originária de tribunal e querela nullitatis, incidente de competência originária de tribunal. 13. ed. reform. Salvador: Ed. JusPodivm, 2016, p. 275.

${ }^{41}$ PINHO, Humberto Dalla Bernardina de. Direito processual civil contemporâneo. vol. 2: processo de conhecimento, cautelar, execução e procedimentos especiais. 3. ed. São Paulo. Saraiva, 2016, p. 907

${ }^{42}$ DONIZETTI, Elpídio. Novo Código de Processo Civil comentado. 2. ed. rev., atual. e ampl. São Paulo: Atlas, 2017, p. 1.349 . 
ajustar, alterar ou aditar o recurso já interposto, e não interpor novo recurso ou recorrer novamente. A preclusão a impede. ${ }^{43}$

Nesse diapasão, o Código de Processo Civil de 2015 não só disponibilizou a possibilidade de modificação da decisão embargada, e ainda, objetivou garantir o princípio do contraditório, concedendo prazo de quinze dias para aditar, alterar ou complementar recurso já interposto, de modo que a parte adversa da decisão modificada não fique desassistida.

\subsection{EFEITOS MODIFICATIVOS VERSUS EFEITOS INFRINGENTES}

A exemplo de Daniel Amorim Assumpção Neves acredita haver uma diferenciação entre embargos de declaração com efeitos modificativos e Embargos de Declaração com efeitos infringentes. Diz que: "Apesar da distinção proposta, é preciso reconhecer que o Superior Tribunal de Justiça, assim como grande parte da doutrina, confunde essas duas espécies de atipicidade dos Embargos de declaração". ${ }^{4}$

Nessa senda, passa-se a demonstrar a possibilidade de diferenciar os dois institutos sob os ensinamentos do doutrinador supracitado.

Os Embargos de Declaração com efeito modificativo são os previstos em lei, especialmente no art. 1.022 do Código de Processo Civil. Nessa hipótese, portanto, não é considerada uma espécie de Embargos atípicos, já que denota da sua utilização comum, ou seja, ao utilizar o recurso de Embargos, por consequência, caberia o efeito modificativo. Nessa seara, somente o efeito da modificação seria atípica e não os Embargos, isso porque, foge dos efeitos naturais da interposição comum dos embargos de declaração.

Por outro lado, os Embargos de Declaração com efeitos infringentes são, como um todo, atípicos. Não guardam, portanto, qualquer intimidade com o art. 1.022 do Código de Processo Civil de 2015, mas de erros incongruentemente viciosos, como por exemplo: "erro manifesto de contagem de prazo, ausência de intimação de uma das partes, revelia

\footnotetext{
${ }^{43}$ DIDIER JUNIOR, Fredie; CUNHA, Leonardo Carneiro. Curso de direito processual civil nos tribunais: recurso, ações de competência originária de tribunal e querela nullitatis, incidente de competência originária de tribunal. 13. ed. reform. Salvador: Ed. JusPodivm, 2016, p. 275.

${ }^{44}$ NEVES, Daniel Amorim Assumpção. Manual de direito processual civil. 9. ed. Salvador: Editora JusPodivm, 2017, p. 1.709.
} 
decretada em razão de a contestação estar perdida no cartório e não ter sido juntada aos autos" ${ }^{25}$. Ou seja, casos atípicos.

A utilização dos embargos de declaração, nesses casos, pode gerar reforma ou até anulação da decisão embargada. Consequentemente, os embargos e seus efeitos serão atípicos, infringentes. ${ }^{46}$

\section{CONSIDERAÇÕES FINAIS}

O desenvolvimento do presente estudo possibilitou uma análise sobre os recursos processuais civis com o advento do Código de Processo Civil de 2015, precisamente sobre os Embargos de Declaração e a possibilidade de efeito modificativo quando de sua utilização.

Foi proposta uma apreciação sobre a utilização dos recursos previstos no art. 994 do diploma processual em vigência, explanando brevemente sobre suas possibilidades, eficácias, modalidades, bem como de seus efeitos, de modo a possibilitar ao leitor um panorama geral sobre eles e servindo também de introito aos Embargos de Declaração.

Sobre os embargos de declaração restou evidente que ele possui o objetivo de aclarar a decisão proferida, seja esclarecendo obscuridade e eliminando contradição, seja suprindo omissão ou corrigindo erro material. Disponibilizou-se também uma visão aprofundada sobre os embargos de declaração e suas nuances, para que chegasse ao ponto fulcral da obra, que seria definir a possibilidade (ou não) de os Embargos de Declaração possuir o chamado efeito modificativo/infringente.

A necessidade de expor o tema se molda na controvérsia que pairou sobre o judiciário, durante décadas, no que se relaciona a utilização do recurso em tela e o possível efeito modificativo. Dessa forma, tentou-se a todo o momento extinguir dúvidas sobre o efeito supramencionado e sua utilização.

Entende-se, dessa forma, que há cristalina possibilidade do efeito modificativo dos embargos de declaração como consequência do manejo de tal recurso (e não por objetivo principal a modificação do julgado),

\footnotetext{
${ }^{45}$ NEVES, Daniel Amorim Assumpção. Manual de direito processual civil. 9. ed. Salvador: Editora JusPodivm, 2017, p. 1.709.

${ }^{46}$ Idem.
} 
ainda, restou evidente que a nova lei processual positivou essa modalidade, não restando dúvidas sobre a sua figuração no ordenamento jurídico pátrio.

Isto posto, quando a decisão proferida conter algum dos pressupostos embargáveis (contradição, omissão, erro material ou obscuridade), caberá o recurso de Embargos de Declaração, e ainda, caso a correção da decisão embargada culmine em sua modificação, tal recurso possuirá o efeito modificativo, permitido expressamente pelo art. 1.024, parágrafo $4^{\circ}$ do Código de Processo Civil de 2015, fato que já vinha sendo aceito pela doutrina e jurisprudência.

Sendo assim, não restam dúvidas quanto a validade do efeito modificativo no que concerne a consequência da utilização dos Embargos de Declaração, ao passo que se amplia a aplicabilidade de tal recurso, garantindo decisões mais completas, cristalinas e eivadas de equívocos que resultem em cunhos decisórios injustos.

\section{REFERÊNCIAS}

ASSIS, Araken de. Manual dos recursos. 1.ed. São Paulo: Editora Revista dos Tribunais, 2016.

BRASIL. Supremo Tribunal Federal (STF). Regimento Interno. Consolidado e atualizado até maio de 2002 por Eugênia Vitória Ribas. Brasília: STF, 2016.

. Tribunal de Justiça do Estado do Rio Grande do Sul (TJ-RS). Recurso Cível n ${ }^{\circ}$ 71000595124. Relatora: Mylene Maria Michel. Diário da Justiça do dia 02/05/2005. Disponível em: <https://tj-rs.jusbrasil.com.br/jurisprudencia/7875748/recurso-civel-71000595124-rs> acesso em: 08 out. 2017.

. TJ-DF. Embargos de declaração no Agravo de instrumento n ${ }^{\circ}$ EMD1

201400200796971.Terceira Turma Cível. Relator: Getúlio de Moraes Oliveira. Brasília, DF, 24 de setembro de 2014. Diário da Justiça do Dia 02/10/2014, p. 98. Disponível em: <https://tj-

df.jusbrasil.co m.br/jurisprudencia/311502517/Embargos-de-declaracao-no-a-agravo-de-instrumentoemd1-201400200796971-agravo-de-instrumento> Acesso em: 24 out. 2017.

. Código de Processo Civil. Lei nº 13.105, de 16 de março de 2015.

. RJ-RS. Embargos de declaração No 71006828719. Quarta Turma Recursal Cível, Turmas Recursais, Relator: Gisele Anne Vieira de Azambuja, Julgado em 17/08/2017. Disponível em: <https://tj-rs.jusbrasil.com.br/jurisprudencia/491284497/Embargos-de-declaracao-ed-71006828719rs> Acesso em: 24 out. 2017.

CÂMARA, Alexandre Freitas. O novo processo civil brasileiro. 2. ed. São Paulo: Atlas, 2016. 
DIDIER JUNIOR, Fredie; CUNHA, Leonardo Carneiro. Curso de direito processual civil: o processo civil nos tribunais, recurso, ações de competência originária de tribunal e querela nullitatis, incidentes de competência originária de tribunal. 13. ed. reform. Salvador: Ed. JusPodivm, 2016.

DONIZETTI, Elpídio. Novo Código de Processo Civil comentado. 2. ed. rev., atual. e ampl. São Paulo: Atlas, 2017.

FERNANDES, Luís Eduardo Simardi. Embargos de declaração: efeitos infringentes, prequestionamento e outros aspectos polêmicos. 3. ed. rev. atual. e ampl. São Paulo: Editora Revista dos Tribunais, 2012.

FAGUNDES, M. Seabra. Dos embargos de declaração. Litis: revista trimestral de direito processual, 5-13, 1976, p. 11. Acesso em: 14 out. 2017.

MARINONI, Luiz Guilherme; ARENHART, Sérgio Cruz; MITIDIERO, Daniel. Novo Código de Processo Civil comentado. 3. ed. rev., atual, e ampl. São Paulo. Editora Revista dos Tribunais, 2017.

NEVES, Daniel Amorim Assumpção. Manual de direito processual civil. 8. ed. Salvador: Ed. JusPodivm, 2016.

Daniel Amorim Assumpção. Manual de direito processual civil. 9. ed. - Salvador: Ed. JusPodivm, 2017.

PINHO, Humberto Dalla Bernardina de. Direito processual civil contemporâneo: processo de conhecimento, cautelar, execução e procedimentos especiais. vol. 2. 3. ed. São Paulo. Saraiva, 2016. 